\title{
BMJ Open Retrospective morphometric study of the suitability of renal arteries for renal denervation according to the Symplicity HTN2 trial criteria
}

\author{
Elisabeth Schönherr, ${ }^{1}$ Rafael Rehwald, ${ }^{1}$ Parinaz Nasseri, ${ }^{2}$ Anna K Luger, ${ }^{1}$ \\ Astrid E Grams, ${ }^{3}$ Julia Kerschbaum, ${ }^{4}$ Peter Rehder, ${ }^{5}$ Johannes Petersen, ${ }^{1}$ \\ Bernhard Glodny ${ }^{1}$
}

To cite: Schönherr E, Rehwald R, Nasseri P, et al. Retrospective morphometric study of the suitability of renal arteries for renal denervation according to the Symplicity HTN2 trial criteria. BMJ Open 2016;6:e009351. doi:10.1136/bmjopen-2015009351

- Prepublication history for this paper is available online. To view these files please visit the journal online (http://dx.doi.org/10.1136/ bmjopen-2015-009351).

ES and RR contributed equally and should therefore be considered co-first authors.

Received 9 July 2015 Revised 31 August 2015 Accepted 12 October 2015

CrossMark

For numbered affiliations see end of article.

\section{Correspondence to}

Professor Johannes Petersen; johannes.petersen@i-med. ac.at

\section{ABSTRACT}

Objective: The aim of this study was to describe the renal arteries of humans in vivo, as precisely as possible, and to formulate an expected value for the exclusion of renal denervation due to the anatomical situation based on the criteria of the Symplicity HTN trials.

Design and setting: In a retrospective cohort study, the renal arteries of 126 patients (57 women, 69 men, mean age $60 \pm 17.2$ years ( $\mathrm{Cl} 57.7$ to 63.6$)$ ) were segmented semiautomatically from high-contrast CT angiographies.

Results: Among the 300 renal arteries, there were three arteries with fibromuscular dysplasia and one with ostial renal artery stenosis. The first left renal artery was shorter than the right $(34 \pm 11.4 \mathrm{~mm}(\mathrm{Cl} 32$ to 36$)$ vs $45.9 \pm 15 \mathrm{~mm}$ (Cl 43.2 to 48.6$) ; p<0.0001)$, but had a slightly larger diameter $(5.2 \pm 1.4 \mathrm{~mm}$ (Cl 4.9 to 5.4$)$ vs $4.9 \pm 1.2 \mathrm{~mm}$ (Cl 4.6 to 5.1$) ; \mathrm{p}>0.05)$. The first left renal arteries were $1.1 \pm 0.4 \mathrm{~mm}(\mathrm{Cl} 0.9$ to 1.3$)$, and the first right renal arteries were $0.3 \pm 0.6 \mathrm{~mm}(\mathrm{Cl} 0.1$ to 0.5$)$ thinner in women than in men $(p<0.05)$. Ostial funnels were up to $14 \mathrm{~mm}$ long. The cross-sections were elliptical, more pronounced on the right side $(p<0.05)$. In 23 cases $(18.3 \%)$, the main artery was shorter than $2 \mathrm{~cm}$; in 43 cases (34.1\%), the diameter was not $>4 \mathrm{~mm}$. Some $46 \%$ of the patients, or $58.7 \%$ when variants and diseases were taken into consideration, were theoretically not suitable for denervation.

Conclusions: Based on these precise measurements, the anatomical situation as a reason for ruling out denervation appears to be significantly more common than previously suspected. Since this can be the cause of the failure of treatment in some cases, further development of catheters or direct percutaneous approaches may improve success rates.

\section{INTRODUCTION}

Arterial hypertension is the leading risk factor for ischaemic cardiac and cerebral vascular disease in humans. Up to $17.2 \%$ of all deaths are attributable to it. At the same

\section{Strengths and limitations of this study}

- The present study is an exact morphometric analysis of all renal arteries in a cohort of patients with computed tomographic angiographies of the abdomen in highest resolution, including the diameter at each point of the vessels, centreline distances and minimal and maximal passage distances.

- Distribution of variants in the study group indicating a representative sample.

- The numerical eccentricity of renal arteries was assessed for the first time, together with renal implantation angles at the aorta and angles of origin.

- Taking the anatomical situation into account, the theoretical possibility of denervation using standard renal denervation devices was assessed in a random series of humans for the first time.

- Retrospective study, no information on the actual presence of hypertension, no intention to treat.

time, arterial hypertension is also the first risk factor for which it was proven that treatment can reduce the cardiovascular morbidity and mortality of affected patients. ${ }^{1}{ }^{2}$ This applies not only to severe arterial hypertension ${ }^{3}$ but also to grade 1 hypertension. ${ }^{4}$ Lowering the diastolic blood pressure by only $5 \mathrm{~mm} \mathrm{Hg}$ reduces the risk of a stroke by at least one-third, and the risk of coronary heart disease by one-fourth. ${ }^{5}$ The reduction in mortality has been demonstrated for the use of various antihypertensive drugs. ${ }^{6}$ After exhausting all non-drug measures, step-by-step treatment is given with core substances that are administered first alone, then in combinations of two and three agents. $^{7} 8$ Nevertheless, a group of about $5-15 \%$ of all patients remains, whose blood pressure cannot be sufficiently reduced in this manner. ${ }^{9}$ According to 
American Heart Association guidelines, ${ }^{9}$ various measures should be undertaken to treat this treatment-refractory hypertension, among them using aldosterone antagonists as a fourth mode of action. An alternative is the endovascular denervation of the renal arteries, a method based on experience with the results of surgical denervation in experimental hypertension. ${ }^{10-}$ ${ }^{14}$ In the HTN3 study, ${ }^{15}$ the safety of the procedure was demonstrated but not the originally anticipated reduction of blood pressure, ${ }^{16}$ possibly due to weaknesses in the design and various bias effects, ${ }^{17}$ although a reduction in blood pressure was demonstrated in another study ${ }^{18}$ - anatomical features could be causes that have not yet been sufficiently investigated for the weaker-than-predicted potency of the method. Variants of the renal arteries-16\% in the Symplicity HTN2 study ${ }^{19}$ - were significantly under-represented in comparison with an expected value of around $38.3 \%$ of the patients. ${ }^{20}{ }^{21}$ It must also be taken into consideration that renal artery variants themselves could be associated with arterial hypertension. ${ }^{22}$ Data on lengths and diameters of the renal arteries in vivo, are rare in literature. $^{23} 24$ Diameters and lengths are dependent on gender $^{23}$ and on the presence of additional vessels. ${ }^{25}$ The data do not reflect the curvature of the vessels in the area, the resulting ovality of the inner lumen, the wall lengths that vary between larger and smaller circumferences, or the fluctuation of the diameters along the course of the vessel. The aims of this study were, therefore, in view of the new techniques of renal denervation, to precisely determine the length, diameter, implantation angle and lumen ovality of renal arteries of humans in vivo, and the impact these features can have on renal denervation.

\section{PATIENTS AND METHODS Ethical considerations}

This study is a retrospective observational study that had no effect on the treatment of patients enrolled. It was therefore not necessary to obtain a vote of approval from the ethics committee for the study. The data were completely deidentified. All conditions of the latest version of the Declaration of Helsinki of the World Medical Association were met.

\section{CT data sets}

The study included CT data sets from 126 consecutive patients who underwent CT angiography of the abdomen. None of the patients had undergone renal denervation. There were 57 women and 69 men with a mean age of $60 \pm 17.2$ years. The indications for the examination were for detection of hepatocellular carcinoma in patients with liver diseases (48 patients; 38.1\%), assessment of abdominal vessels, for example, prior to live kidney donation or endovascular repair of an aneurysm (41 patients; 32.5\%), suspected occlusion of the superior mesenteric artery (16 patients; 12.7\%), pancreatic cancer (15 patients; 11.9\%) and abdominal haemorrhage in six patients $(4.8 \%)$. No additional patient-related parameters were recorded.

\section{Inclusion and exclusion criteria}

A precondition for the inclusion of the data sets was high-contrast imaging of the aorta of more than 300 Hounsfield units at the level of the renal artery origins in order to ensure reliable detection and excellent segmentability of the vessels. The kidneys and their arteries had to be imaged completely. Exclusion criteria were any movement artefacts in the images and images with collimation $>0.625 \mathrm{~mm}$. A total of 349 examinations were viewed that had been performed between December 2008 and August 2012. Of these, 38 examinations were not used because the kidneys and renal arteries were not completely imaged in an arterial phase; 11 because movement artefacts were present. In the remaining cases $(\mathrm{n}=174)$, the collimation was $>0.625 \mathrm{~mm}$, and/or the specified noise factor was not reached with the result that the radiation dose applied was not sufficient for unambiguous segmentation.

\section{Technical parameters of the examinations}

All examinations were performed on one of two 64-slice CT scanners from General Electric (Discovery 750 or LightSpeed VCT, General Electric Company, Fairfield, Connecticut, USA). Jopamiro 370 (Bracco Imaging S.p. A., Milan, Italy) or Ultravist 370 (Bayer Schering Pharma AG, Berlin, Germany) was administered as contrast agent with the dosage corresponding to 1.5 times the body weight $(\mathrm{kg})$ in $\mathrm{mL}$. It was injected using a pressure injector (Missouri, Ulrich Medical, Ulrich GmbH \& Co $\mathrm{KG}$, Ulm, Germany) after a $30 \mathrm{~mL}$ bolus of an isotonic saline solution with a flow of $4-5 \mathrm{~mL} / \mathrm{s}$. Finally, a $30 \mathrm{~mL}$ chaser bolus was administered. The correct start time of the device was determined using the bolus tracking programme (SmartPrep, General Electric Company, Fairfield, Connecticut, USA). Using a dose modulation programme that affects the tube current, a noise factor of $<21$ was sought for each examination. The tube voltage was $120 \mathrm{KV}$, revolution time $0.6 \mathrm{~s}$, collimation was $64 \times 0.6 \mathrm{~mm}$, spacing was $0.62 \mathrm{~mm}$, and pitch was $0.984 / 1$.

\section{Implementation of the study}

The examinations were viewed and assessed in the Picture Acquisition and Communication System (IMPAX EE R20 VII P1, Agfa HealthCare NV, Mortsel, Belgium). The arterial phase of the examination was sent as a DICOM file to an image postprocessing console (Advantage Workstation 4.6/VolumeShare 5, General Electric Company, Fairfield, Connecticut, USA). All segmentations were performed in the VolumeShare 5 programme. The segmentation of the deidentified data sets was conducted by consensus of two examiners (ES and PN) after the joint evaluation of the anatomical situation with a third examiner who verified all results. Renal arteries were assessed with respect to changes and 
pathologies by two board-certified radiologists in consensus (GB and JP or AG). The data were deidentified and transferred to an Excel sheet.

\section{Centreline analyses}

The starting points for the calculation of the centrelines through the renal arteries were placed in the vicinity of the aortic wall circumference opposite to the ostium to completely map the ostial funnel of the artery in the curved reconstructions. A second point was placed directly before the ostium of the renal artery, a third point in the ostial funnel, and further points at every centimetre along the course of the artery. The location of the last point was chosen to be in one of the two arterial divisions distal to the first bifurcation of the renal artery. The centreline and a straightened image in a curved reconstruction were then created automatically. Figure 1A shows the determination of the midpoint of the conic section of the ostial funnel of the left renal artery, defined by the intersection of the extension of the centreline through the renal artery on the aortic side with a line along the aortic wall (dashed line). After defining the end of the renal artery by a plane perpendicular to the centreline that does not cross the carina of the first bifurcation (figure 1B), the lengths of the centreline, the longest and the shortest transverse lines were measured. At the origin of the renal artery and every $2 \mathrm{~mm}$ along its course, the cross-sections and the minimum, mean and maximum diameters were determined automatically (figure 1C). Each segmented cross-sectional area was checked at greatly magnified slices perpendicular to the centreline (figure 1D). The maximum curvature angles of the renal arteries were determined in three-dimensional reconstructions perpendicular to the respective curvature plane (figure $1 \mathrm{E}$ ). The renal artery implantation angles ${ }^{26}$ were determined in the plane defined by the centreline of the aorta and the renal artery (figure $1 \mathrm{~F}$ ). In order to simplify things, the cross-sections of the arteries were considered to be elliptical, so the numerical eccentricity, $\varepsilon$, could be calculated with 'a' as the semimajor axis and ' $b$ ' as the semiminor axis using the formula given below.

$$
\varepsilon=\frac{\sqrt{\mathrm{a}^{2}-\mathrm{b}^{2}}}{\mathrm{a}}
$$

In addition, age and gender of the patient, length of the kidneys, number of arteries, insertion angle in the transverse plane, and pathologies, were taken from the image data sets. The extent of atherosclerosis of the renal arteries was determined based on Friesinger score. ${ }^{27}$ The scores of the six-point scale that was originally intended for the assessment of the coronary arteries are: 0: no abnormalities; 1: wall irregularities or trivial luminal narrowing of $<29 \%$; 2: localised luminal narrowing of 30-68\%; 3: diffuse, multiple lesions and at least two sites of luminal narrowing of $30-68 \%$; 4 : at least one luminal narrowing of $69-100 \%$ without $100 \%$ occlusion; 5: complete obstruction without distal contrasting. ${ }^{27}$

\section{Statistical analysis}

Descriptive statistics were generated using Excel (Office 2007, Microsoft, Seattle, Washington, USA). The graphical presentations were made with Prism 5 (GraphPad Software Inc, La Jolla, California, USA). Comparisons between categorical variables were made using Fisher's exact test, comparisons between two groups with the nonparametric Mann-Whitney $U$ test, and between three and more groups using the Kruskal-Wallis test, or one-way analysis of variance, as appropriate. The correlation between the extent of atherosclerosis of the renal arteries and their diameters was examined using Spearman's rank correlation coefficient. Factors influencing the diameters and lengths of the first right and left renal arteries were determined by linear regression models adjusted to the two target parameters initially including all variables, and then based on this model finally adjusted using forward stepwise selection. For this purpose, the SPSS programme (SPSS V.20, IBM, Armonk, New York, USA) was used. A $p<0.05$ was considered significant.

\section{RESULTS}

\section{Descriptive statistics}

The 126 patients had 124 right and 125 left kidneys with a total of 300 arteries. These were 124 first right and 125 first left arteries, 24s right and 24s left arteries, two-third right and one-third left artery. Table 1 shows the combinations of the variants in the patients. One patient had bilateral and another had unilateral fibromuscular dysplasia, and one patient had an atherosclerotic ostial renal artery stenosis on the right side. One hundred and sixty-three patients $(54.3 \%)$ had a Friesinger score of 0 ; $93(31.0 \%)$ of $1 ; 35(11.7 \%)$ of $2 ; 8(2.7 \%)$ of $3 ; 1$ $(0.3 \%)$ of 4 , and 0 patients of 5 .

\section{Dimensions of the arteries}

The data were distributed normally. The first left renal artery was statistically significantly shorter than the first right renal artery, but the diameters were somewhat larger. The second left renal arteries were shorter and thinner than the second right arteries (table 2). The first left renal arteries were $1.1 \pm 0.4 \mathrm{~mm}$ (CI 0.9 to 1.3 ) and the first right arteries $0.3 \pm 0.6 \mathrm{~mm}$ (CI 0.1 to 0.5 ) thinner in women than in men. The second left renal arteries were $0.7 \pm 0.6 \mathrm{~mm}$ (CI 0.4 to 0.9 ), and the second right arteries were $0.7 \pm 0.4 \mathrm{~mm}$ (CI 0.5 to 0.8 ) thinner in women than in men. The implantation angles were usually directed caudally and were slightly steeper on the right than the left for first and second renal arteries. The second renal arteries arose a little further anterior compared with first arteries (table 1). On the right side, their course was mainly preaortic. The almost always present curvatures were mostly directed cranially, while second or third curvatures were much less common. 
Figure 1 Segmentation process of the renal arteries.

Determination of the midpoint of the conic section of the ostial funnel $(A)$, and definition of the end of the renal artery (B). After generation of the centreline measurement of the length of the centreline, the longest and shortest transverse lines through the artery, and of cross-sections, minimum, mean and maximum diameters every $2 \mathrm{~mm}$ along the vessel (C). Manual check of the accuracy (D). Then determination of the curvature angles of the artery $(E)$, and of the renal artery implantation angles $(F)$.
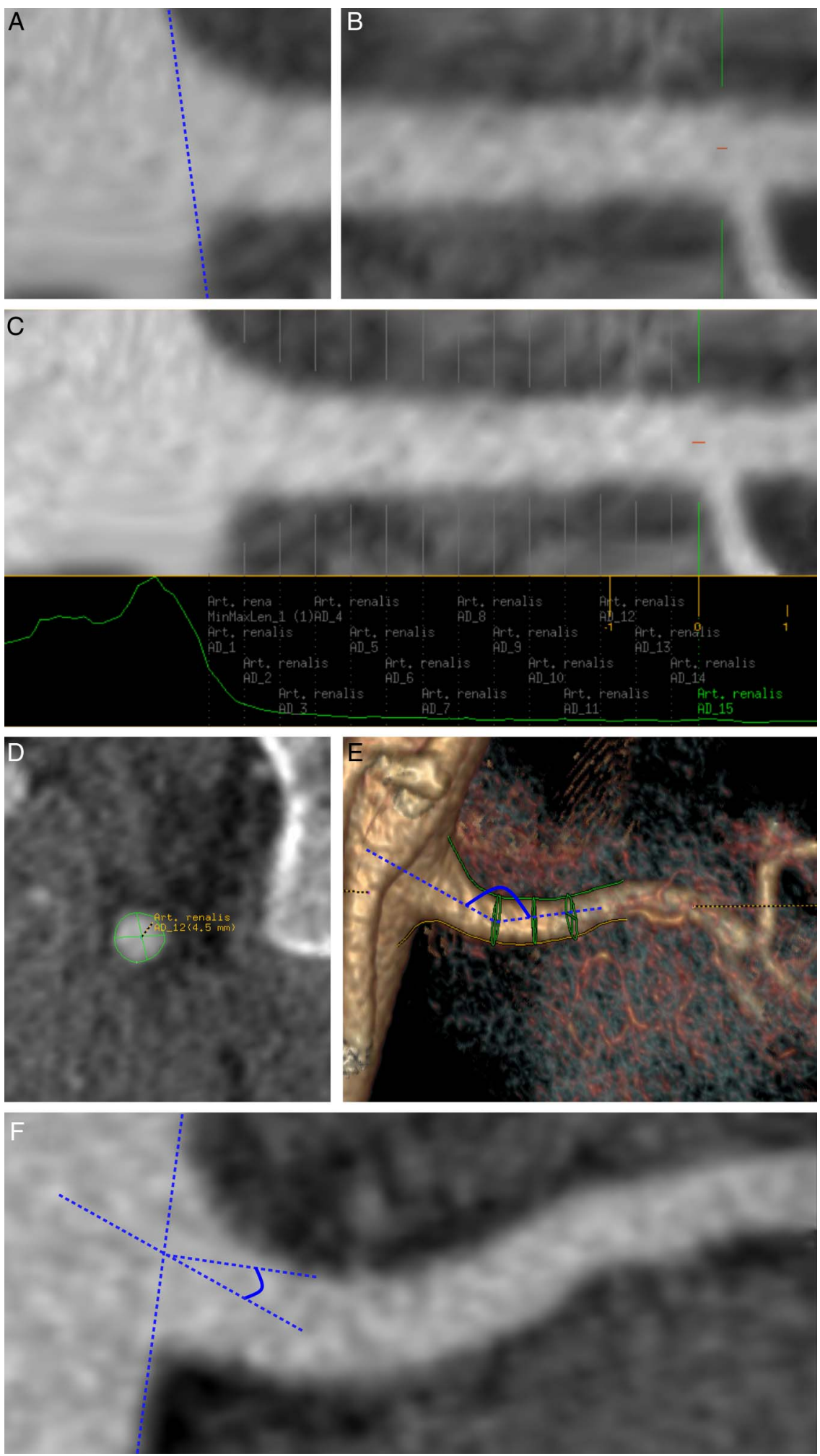

The numerical eccentricity of all renal arteries indicated an elliptical cross-section, which was more pronounced on the right side (table 2).

\section{Diameter profiles of the renal arteries}

The first renal arteries on both sides had wider and longer ostial funnels than the second arteries. These funnels were most pronounced on the left side, where they were up to $14 \mathrm{~mm}$ long. The main arteries widened somewhat, at about $3-4 \mathrm{~cm}$ distal to the ostium after a segment with a relatively constant diameter distal to the funnel. The second renal arteries were thinner, had shorter ostial funnels, and no distal widening (figure 2A-D). 
Table 1 Description of the cohort

\begin{tabular}{|c|c|}
\hline Variables & $\mathbf{n}$ \\
\hline Patients & 126 \\
\hline Women & 57 \\
\hline Men & 69 \\
\hline Nephrectomies & 3 \\
\hline Kidneys on the right side & 124 \\
\hline First arteries on the right side & 124 \\
\hline Second arteries on the right side & 24 \\
\hline Third arteries on the right side & 2 \\
\hline Kidneys on the left side & 125 \\
\hline First arteries on the left side & 125 \\
\hline Second arteries on the left side & 24 \\
\hline Third arteries on the left side & 1 \\
\hline $\begin{array}{l}\text { Patients with } 1 \text { artery on the right, and } 1 \text { on the } \\
\text { left side }\end{array}$ & 82 \\
\hline $\begin{array}{l}\text { Patients with } 1 \text { artery on the right, and } 2 \text { on the } \\
\text { left side }\end{array}$ & 20 \\
\hline $\begin{array}{l}\text { Patients with } 2 \text { arteries on the right, and } 1 \text { on } \\
\text { the left side }\end{array}$ & 19 \\
\hline Patients with 2 arteries on both sides & 3 \\
\hline $\begin{array}{l}\text { Patients with } 1 \text { artery on the right, and } 3 \text { on the } \\
\text { left side }\end{array}$ & 1 \\
\hline $\begin{array}{l}\text { Patients with } 3 \text { arteries on the right, and } 1 \text { on } \\
\text { the left side }\end{array}$ & 2 \\
\hline $\begin{array}{l}\text { Patients with } 2 \text { arteries on the right, and } 0 \text { on } \\
\text { the left side }\end{array}$ & 1 \\
\hline $\begin{array}{l}\text { Patients with } 0 \text { arteries on the right, and } 1 \text { artery } \\
\text { on the left side }\end{array}$ & 2 \\
\hline Fibromuscular dysplasia & 3 \\
\hline $\begin{array}{l}\text { Atherosclerotic stenosis of the origin of the main } \\
\text { renal arteries }\end{array}$ & 1 \\
\hline Horseshoe kidney & 1 \\
\hline All arteries & 300 \\
\hline
\end{tabular}

\section{Visualisation of the length and diameter of the renal} arteries

Figure 3A-D shows, for each measured distance from the ostia, the number of vessels that had a diameter of more than $4 \mathrm{~mm}$ at this point and had not yet branched. The diameters of $33.1 \%$ of the first right renal arteries, and $28 \%$ of the first left renal arteries fell to $<4 \mathrm{~mm}$ within the first $2 \mathrm{~cm}$ distal to the origin, while only $6.5 \%$ of the right and $10 \%$ of the left arteries did not reach a length of $2 \mathrm{~cm}$. All second right and left arteries reached a length of $>2 \mathrm{~cm} ; 41.6 \%$ of the right, but only $12 \%$ of the left vessels had a diameter $>4 \mathrm{~mm}$. Two centimetre distal to the origin, 36 arteries $(12.8 \%)$ were even thinner than $3 \mathrm{~mm}, 7$ arteries $(2.5 \%)$ thinner than $2 \mathrm{~mm}$, and 1 artery $(0.4 \%)$ thinner than $1.5 \mathrm{~mm}$.

\section{Influencing factors on the length and diameter of the renal arteries}

The strongest positive influencing factor on the diameter of the first right renal arteries was the length of the right kidney $(\beta=0.440 ; p<0.0001)$, before the diameter of the left main artery $(\beta=0.343 ; p<0.0001)$, and multiplicity of the right renal arteries $(\beta=-0.216 ; \mathrm{p}=0.019)$.
The length of the left kidney had the greatest effect on the diameter of the first left renal artery $(\beta=0.448$; $p<0.0001)$, before age $(\beta=-0.241 ; p=0.008)$. The length of the right renal arteries increased with age $(\beta=0.246$; $\mathrm{p}=0.010$ ) and with anterior position of their origins $(\beta=0.257 ; p=0.016)$. The length of the left renal arteries increased with anterior position of their origins $(\beta=0.213 ; p=0.025)$. The Friesinger score, and thus, the extent of atherosclerosis of the renal arteries had no effect on the diameters of the vessels (Spearman $\rho=-0.102, p>0.05)$.

\section{Presentation of obstacles to denervation in the population studied}

According to the exclusion criteria of the Symplicity studies ${ }^{19} 46 \%$ of the patients would not be eligible for denervation (table 3). If multiple renal arteries and diseases of the renal arteries are taken into consideration, this figure amounts to $58.7 \%$.

\section{DISCUSSION}

This study was the first to present exact morphometric data on the renal arteries in a sample of 126 persons in vivo. Although previous data from literature did not take the curves of the vessels into account, the measurements of the lengths of the renal arteries were confirmed, but the inner diameters of the vessels were up to $1 \mathrm{~mm}$ less than has been assumed until now. The lengths were equal in men and women, but the inner diameter of the first right and left renal artery was statistically highly significantly smaller in women than in men. The cross-sections of the renal arteries were usually slightly ellipsoid, more pronounced on the right than on the left side. However, some of the vessels converged to a paraboloid cross-section. The implantation angles of the right renal arteries were somewhat more acute with respect to the longitudinal axis of the aorta than those of the left arteries. Some $46 \%$ of persons did not fulfil the anatomical requirements for renal denervation set in the Symplicity studies. When multiple renal arteries and diseases of the renal arteries were taken into consideration, this figure was $58.7 \%$.

In comparison with the present data and literature, ${ }^{20} 22$ patients with renal artery variants are under-represented in studies on renal denervation. For example, in a study on the 'anatomic distribution of periarterial sympathetic nerves in 20 cadavers, only 40 renal arteries were found. ${ }^{28}$ In the Symplicity HTN2 trial, ${ }^{19} 30$ of 190 eligible patients $(16 \%)$ were excluded for one of three anatomical reasons, namely, length of the renal arteries $<2 \mathrm{~cm}$, diameter $<4 \mathrm{~mm}$ or the presence of 'more than one main renal artery'. In the ENCOReD study, patients with multiple renal arteries were accepted, ${ }^{29}$ but the exclusion rate of $17 \%$ was very similar to that of the HTN2 trial. ${ }^{19}$ There are several possible interpretations for these discrepancies. In the Symplicity HTN2 study, 'renal artery anatomical screening with renal duplex' 


\begin{tabular}{|c|c|c|c|c|c|c|c|c|c|c|c|}
\hline & & \multicolumn{4}{|c|}{ Women } & \multicolumn{4}{|l|}{ Men } & \multirow[b]{2}{*}{ Unit } & \multirow{2}{*}{$\begin{array}{l}\text { Significant } \\
\text { value }\end{array}$} \\
\hline & & Mean & SD & \multicolumn{2}{|l|}{$\mathbf{C l}$} & Mean & SD & \multicolumn{2}{|l|}{$\mathbf{C l}$} & & \\
\hline \multicolumn{2}{|l|}{ Length of the right kidney } & 100.6 & 14.5 & \multicolumn{2}{|l|}{96.8 to 104.5} & 109.3 & 10.4 & \multicolumn{2}{|c|}{106.8 to 111.8} & $\mathrm{~mm}$ & 0.0007 \\
\hline \multicolumn{2}{|l|}{ Length of the left kidney } & 103.4 & 17.89 & \multicolumn{2}{|l|}{98.56 to 108.1} & 113.4 & 11.6 & \multicolumn{2}{|c|}{110.7 to 116.2} & $\mathrm{~mm}$ & 0.0002 \\
\hline \multicolumn{2}{|l|}{ Length of the 1st renal artery on the right side } & 44.75 & 14.07 & \multicolumn{2}{|l|}{40.94 to 48.55} & 46.87 & 15.84 & \multicolumn{2}{|c|}{43 to 50.8} & $\mathrm{~mm}$ & 0.4257 \\
\hline \multirow{2}{*}{\multicolumn{2}{|c|}{$\begin{array}{l}\text { Length of the } 2 \text { nd artery on the right side } \\
\text { Length of the } 1 \text { st renal artery on the left side }\end{array}$}} & 49.23 & 15.71 & \multicolumn{2}{|l|}{34.7 to 63.8} & 57.84 & 17.48 & \multicolumn{2}{|c|}{49.2 to 66.5} & $\mathrm{~mm}$ & 0.3326 \\
\hline & & 34.2 & 9.6 & \multicolumn{2}{|l|}{31.6 to 36.8} & 33.9 & 12.7 & \multicolumn{2}{|c|}{30.8 to 36.9} & $\mathrm{~mm}$ & 0.9899 \\
\hline \multicolumn{2}{|l|}{ Length of the 2 nd renal artery on the left side } & 40.1 & 7.32 & \multicolumn{2}{|l|}{34.5 to 45.7} & 48.6 & 15.8 & \multicolumn{2}{|c|}{39 to 58.1} & $\mathrm{~mm}$ & 0.1815 \\
\hline \multicolumn{2}{|c|}{ Diameter of the $1 \mathrm{st}$ right renal artery $2 \mathrm{~cm}$ distal of its origin } & 4.5 & 1 & 4.2 to 4.7 & & 5.2 & 1.3 & \multicolumn{2}{|c|}{4.9 to 5.5} & $\mathrm{~mm}$ & 0.0002 \\
\hline \multicolumn{2}{|c|}{$\begin{array}{l}\text { Diameter of the } 2 \text { nd right renal artery } 2 \mathrm{~cm} \text { distal of its } \\
\text { origin }\end{array}$} & 3.3 & 1.3 & 1.9 to 4.6 & & 4.3 & 1.4 & \multicolumn{2}{|c|}{3.6 to 5} & $\mathrm{~mm}$ & 0.1420 \\
\hline Diameter of the $1 \mathrm{st}$ left renal artery $2 \mathrm{~cm}$ dista & & 4.7 & 1.4 & 4.3 to 5.1 & & 5.6 & 1.2 & 5.3 & to 6 & $\mathrm{~mm}$ & $<0.0001$ \\
\hline Diameter of the $2 \mathrm{nd}$ left renal artery $2 \mathrm{~cm}$ dist & of its origin & 3.1 & 0.8 & 2.5 to 3.7 & & 3.3 & 1.6 & 2.3 & to 4.2 & $\mathrm{~mm}$ & 0.8144 \\
\hline & Right & & & & Left & & & & & & Significant \\
\hline & Mean & & SD & $\mathbf{C l}$ & Mean & & & SD & $\mathrm{Cl}$ & Unit & value \\
\hline Length of the 1st renal artery (centreline) & 45.9 & & 15 & 43.2 to 48.6 & 34 & & & 11.4 & 32 to 36 & $\mathrm{~mm}$ & $<0.0001$ \\
\hline $\begin{array}{l}\text { Minimal transit distance 1st renal artery } \\
\text { (concavities) }\end{array}$ & 44.5 & & 15.4 & 41.8 to 47.3 & 32.4 & & & 11 & 30.4 to 34.4 & $\mathrm{~mm}$ & $<0.0001$ \\
\hline $\begin{array}{l}\text { Maximal transit distance 1st renal artery } \\
\text { (convexities) }\end{array}$ & 52.2 & & 15.5 & 49.4 to 55 & 40.2 & & & 12.4 & 38 to 42.4 & $\mathrm{~mm}$ & $<0.0001$ \\
\hline $\begin{array}{l}\text { Diameter of the } 1 \mathrm{st} \text { renal artery }(2 \mathrm{~cm} \text { distal } \\
\text { of the origin) }\end{array}$ & 4.9 & & 1.2 & 4.6 to 5.1 & 5.2 & & & 1.4 & 4.9 to 5.4 & $\mathrm{~mm}$ & 0.1459 \\
\hline Length of the 2 nd renal artery (centreline) & 55.4 & & 17.1 & 48.4 to 62.5 & 45.1 & & & 13.4 & 39.2 to 51.1 & $\mathrm{~mm}$ & 0.0218 \\
\hline $\begin{array}{l}\text { Minimal transit distance } 2 \text { nd renal artery } \\
\text { (concavities) }\end{array}$ & 52.8 & & 20.4 & 44.4 to 61.3 & 44.7 & & & 13.6 & 38.6 to 50.7 & $\mathrm{~mm}$ & 0.0636 \\
\hline $\begin{array}{l}\text { Maximal transit distance } 2 \text { nd renal artery } \\
\text { (convexities) }\end{array}$ & 60.4 & & 18.9 & 52.5 to 68.2 & 49.7 & & & 13.7 & 43.6 to 55.7 & $\mathrm{~mm}$ & 0.0273 \\
\hline $\begin{array}{l}\text { Diameter of the } 2 \text { nd renal artery }(2 \mathrm{~cm} \text { distal } \\
\text { of the origin) }\end{array}$ & 4.1 & & 1.4 & 3.5 to 4.7 & 3.2 & & & 1.3 & 2.6 to 3.8 & $\mathrm{~mm}$ & 0.0208 \\
\hline Length of the 3rd renal artery (centreline) & 60.1 & & 22.9 & NA & 16.2 & & & NA & NA & $\mathrm{mm}$ & NA \\
\hline $\begin{array}{l}\text { Minimal transit distance 3rd renal artery } \\
\text { (concavities) }\end{array}$ & 59.2 & & 21.6 & NA & 16.2 & & & NA & NA & $\mathrm{mm}$ & NA \\
\hline $\begin{array}{l}\text { Maximal transit distance 3rd renal artery } \\
\text { (convexities) }\end{array}$ & 68.4 & & 27.8 & NA & 21.9 & & & NA & NA & $\mathrm{mm}$ & NA \\
\hline $\begin{array}{l}\text { Diameter of the } 3 r d \text { renal artery }(2 \mathrm{~cm} \text { distal } \\
\text { of the origin) }\end{array}$ & 3.8 & & 0.6 & NA & 2.7 & & & NA & NA & $\mathrm{mm}$ & NA \\
\hline Numerical eccentricity of the 1 st renal artery & $0.51(11>0.7$ & $>0.8)$ & 0.12 & 0.48 to 0.53 & 0.47( & $(4>0.7)$ & & 0.12 & 0.45 to 0.49 & No unit & 0.0284 \\
\hline Numerical eccentricity of the 2 nd renal artery & $0.59(6>0.7$ & $0.8)$ & 0.15 & 0.53 to 0.66 & 0.57 & $(4>0.7)$ & & 0.12 & 0.51 to 0.61 & No unit & 0.3864 \\
\hline Implantation angle 1st renal artery & 42.4 (caudal & & 18.4 & 39.1 to 45.6 & 34.2( & (caudally) & & 12.8 & 32 to 36.5 & Degree & $<0.0001$ \\
\hline Implantation angle 2 nd renal artery & 37.6 (caudal & & 21.7 & 28.2 to 46.9 & 28.3 & (caudally) & & 22.7 & 16.6 to 40 & Degree & 0.2505 \\
\hline Implantation angle 3rd renal artery & - & & - & - & - & & & - & - & - & - \\
\hline $\begin{array}{l}\text { Origin angle from the aorta in transversal } \\
\text { planes, 1st renal arteries }\end{array}$ & 65.1 (antero & ral) & 13.8 & 62.7 to 67.5 & 91.5 & (lateral) & & 17.6 & 88.4 to 94.6 & Degree & $<0.0001$ \\
\hline
\end{tabular}




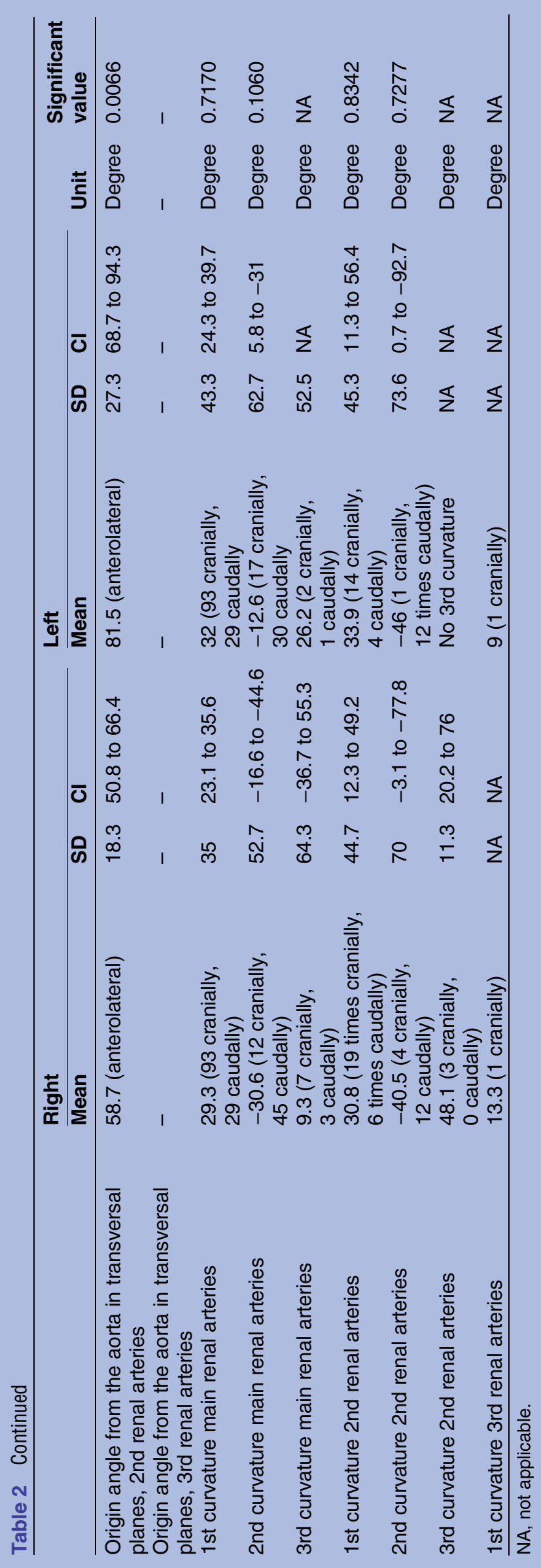

sonography was also allowed as a method to check the inclusion or exclusion criteria. ${ }^{19}$ However, additional renal arteries were generally not adequately examined or even identified ${ }^{30}$ by sonography if their existence was even taken into consideration, which is not the case in most studies; ${ }^{31}$ moreover, its accuracy varies greatly because it is "notoriously operator-dependent'. ${ }^{31}$ This may be a reason for the remarkably low incidence of additional renal arteries in the studies on renal denervation.

In most of the studies, preinterventional evaluation of the anatomy of the renal arteries using MRI or CT was mandatory. ${ }^{29}$ However, even using these methods, the detectability of additional renal arteries depends on technical parameters such as the dose of radiation or contrast agent, the correct timing of imaging in relation to the administration of contrast, the resolution selected, etc. If the contrast is insufficient, or artefacts are present, some additional renal arteries may not be detected or visualised for technical reasons.

Therefore, if the large first artery was considered to be technically feasible to treat, it thus might have been treated. This 'softening' of the inclusion criteria ${ }^{29}$ that was later consciously accepted could be an explanation for the lack of effect of renal denervation in some patients. Accordingly, it was shown in a first clinical trial that patients with a single renal artery benefit more from renal denervation than those with multiple renal arteries. $^{32}$ This observation supports the hypothesis that every renal artery in humans is accompanied by afferent and efferent nerves, however, no evidence of this has yet been found in humans.

The few investigations of the distribution of the sympathetic nervous system with respect to the renal arteries in humans show that a large portion of the fibres run at a distance of only a few millimetres from the lumen of the arteries, ${ }^{28} 33$ only very few at a distance of $>10 \mathrm{~mm}$. According to Atherton et $a l^{33}$ more than $90 \%$ of the fibres are found no further than $2 \mathrm{~mm}$ from the lumen. There are markedly more nerves located anterior, superior or inferior to the arteries than posterior to them, and the number decreases in the distal direction. ${ }^{28}$ It is known for various mammals that afferent fibres can be located in the posterior tracts between T10 and L4, ${ }^{34} 35$ and efferent fibres between T12 and L3. ${ }^{34}{ }^{36}$ This is the area in humans where most of the additional renal arteries are found, ${ }^{37}$ so regardless of the level of origin of the arteries, the same number of nerves should be expected.

In this sample, $35.7 \%$ of the patients had more than one renal artery on the right or left side, a figure that is within the range of frequencies from other studies. ${ }^{25} \mathrm{In}$ $18.6 \%$ of the patients, a 'main artery' was no more than $2 \mathrm{~cm}$ long, and in $34.1 \%$ of the patients, the diameter was $<4 \mathrm{~mm}$ at a location $<2 \mathrm{~cm}$ from the ostium, so that after exact measurement, taking the three patients with fibromuscular dysplasia into account, $58.7 \%$ of the patients in this study would not be eligible for 

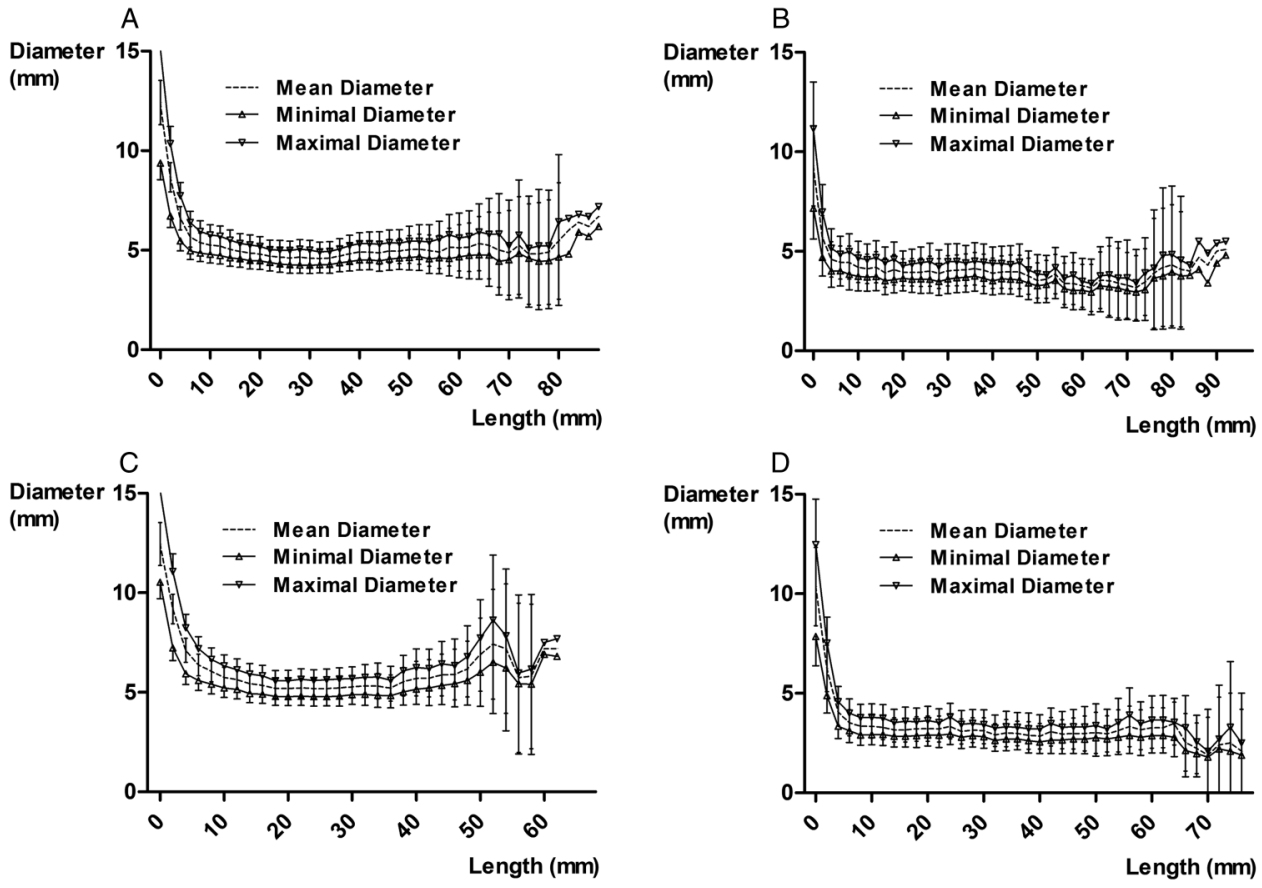

Figure 2 Diameter profiles of the renal arteries. Maximum (upright triangles), mean (dashed line) and minimal diameters (lying triangles) in $\mathrm{mm}$ are plotted on the axis of ordinate over the distance from the midpoint of the ostial funnel on the abscissa every $2 \mathrm{~mm}$ along the vessel. Ostial funnels, and diameter courses of the first right $(A)$, second right $(B)$, first left $(C)$ and second left renal arteries (D) are clearly visible.

denervation according to the Symplicity criteria, ${ }^{19}$ and $46.2 \%$ would still not be eligible according to the European Network Coordinating Research on Renal Denervation criteria. ${ }^{29}$ This figure is more than twice the magnitude indicated in the renal denervation studies. Women in particular are at a significant disadvantage compared with men regarding the use of the method because of up to $1 \mathrm{~mm}$ smaller diameter of the renal arteries. It should be considered that, due to the anatomical obstacles, the technical success of
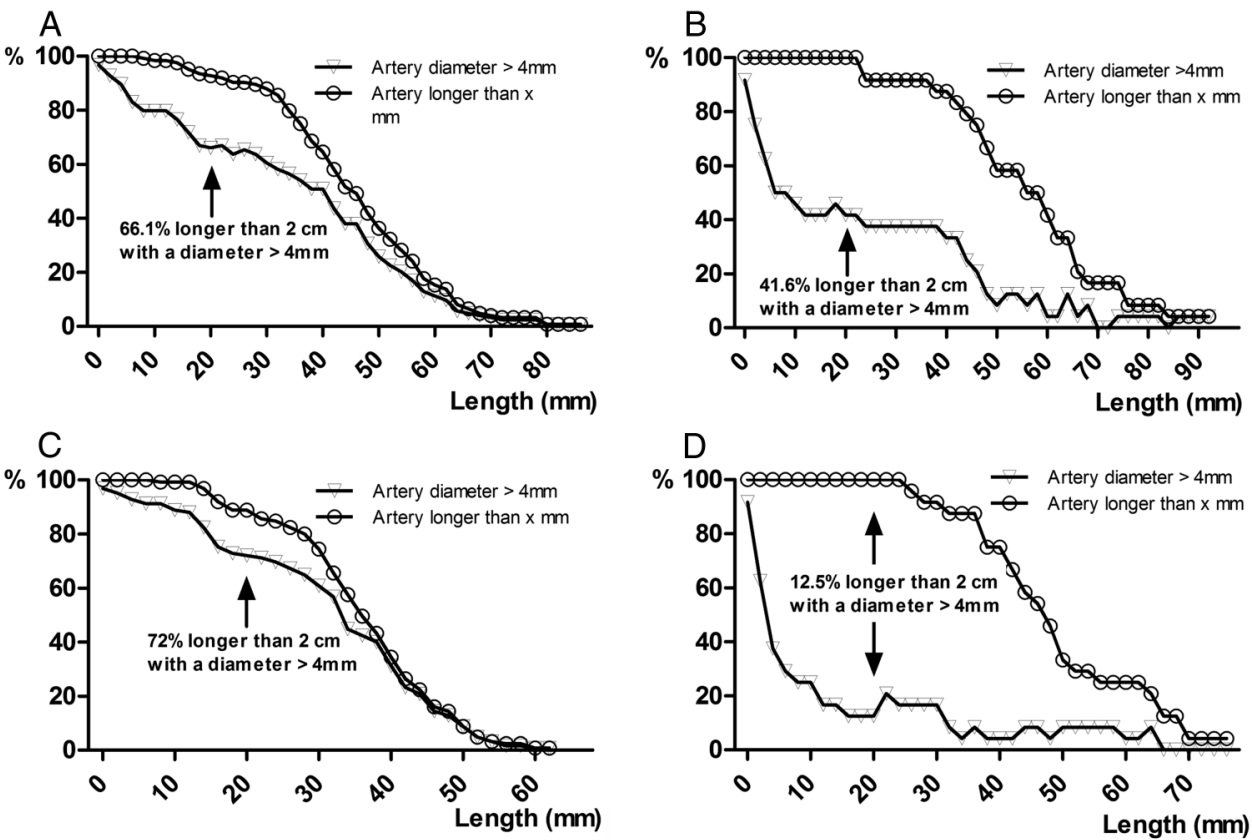

Figure 3 Number of vessels that had not yet branched and had a diameter of more than $4 \mathrm{~mm}$ at each measured distance from the ostia. Black arrows highlighting the situation $2 \mathrm{~cm}$ distally to the midpoint of the ostial funnel of the first right (A), second right $(B)$, first left (C) and second left renal arteries (D). These are the Symplicity criteria. 




denervation is frequently not as optimal as was previously assumed, especially in women.

Furthermore, other causes for the failure of treatment in renal denervation trials have already been identified and substantiated, ${ }^{38}$ especially regarding the Symplicity HTN3 trial. ${ }^{39}$ These were the limited previous experiences with the techniques of renal denervation on the part of some of the cardiologists involved, the learning curve that some of these physicians had to overcome during the trial, and the fact that around one-third of all operators had contributed only a single examination. The failure to apply a confirmatory test for renal denervation hindered all the examinations, and it was ultimately found that the denervations were incomplete and were not homogeneous among the patients. It is therefore probable that the extent of denervations in the studies was typically suboptimal. ${ }^{38}$ These observations are very consistent with the hypothesis expressed based on this trial that the renal denervation results could have been incomplete because of the anatomical situation.

The exclusion criteria for renal denervation, namely a renal artery diameter $<4 \mathrm{~mm}$ and a length $<2 \mathrm{~cm}$, had initially been selected entirely arbitrarily. There had been no prior or experimental studies in this respect. The rationale for this action was, on the one hand, that due to the large diameter, the inflow of blood should ensure sufficient cooling, and on the other hand that due to the length of the vessels, it would be possible to perform ablation on at least five individual sites at $5 \mathrm{~mm}$ intervals in a spiral arrangement to prevent the feared complication of renal artery stenosis or aneurysm, and to minimise the damage to the artery. Five radio frequency (RF) doses were considered sufficient to achieve circumferential denervation. The development of stenosis proved to be very rare, while aneurysms have never been observed. The safety measures mentioned may therefore have been overstated.

Failure to meet the criteria, namely ablation of thinner or shorter vessels, is of course not necessarily the cause of the complete failure of treatment. However, for many reasons, a lower probability or lesser extent of success must be anticipated. The smaller the diameter of a renal artery is, the greater the probability that a second renal artery will be found..$^{25}$ Some $12.8 \%$ of renal arteries have a diameter of $<3 \mathrm{~mm}, 2.5 \%<2 \mathrm{~mm}$ and $0.4 \%<1.5 \mathrm{~mm}$, which makes ablation considerably more difficult or impossible, even with the latest devices. In cases such as this, a percutaneous, not transarterial approach, could be a possible option that is currently being tested in various studies. The lumens of renal arteries are very rarely round. The simplified crosssection of the vessel usually corresponds to a circle-like ellipse. In a couple of patients, however, $\varepsilon$ was over 0.7 , thus approaching a paraboloid shape. In practice, this means that a two-dimensional curved catheter may have two preferred positions in these vessels, aligned on the semimajor axis. The curvature angle that the catheter 
must assume on its way from the aorta to the ostium of the renal artery is likely to be relevant. The more this angle deviates from the preshaped curvature of a catheter, the greater the tension in the catheter, and the more likely there will be stable directions of rotation for the catheter that lead to partial relaxation, and unstable directions of rotation that can be maintained by the operator only by active application of torque. The forces described could prevent the circumferential coverage of the cross-section for denervation on the one hand, but also change the shape and curvature of the arteries by pressure and shear forces, and ultimately have a traumatic effect. The disadvantage of using guide catheters to remedy this is that they cover the ostium, which shortens the segment that can be denervated. The steep implantation angles in caudal direction on both sides suggest that approaches via the upper limbs may be favourable.

In general, the data with respect to the length of the renal arteries are consistent with those from the literature. ${ }^{24}$ However, the diameters of the first right and left renal arteries measured in this study, with $4.9 \pm 1.2$ and $5.2 \pm 1.4 \mathrm{~mm}$, respectively, are approximately $1 \mathrm{~mm}$ lower than those in the literature, where the not gendercorrected values are between 5.71 \pm 0.83 and 6.9 $\pm 0.2 \mathrm{~mm} .{ }^{24}$ The influencing factors on the diameters of the renal arteries that were defined are plausible-the lack of effect of the extent of atherosclerosis on the diameters of the renal arteries can likely be attributed to the fact that most renal arteries have scores of 0 and 1 , that is, nil to slight atherosclerotic changes.

The strengths of this study are that the largest and smallest diameters of renal arteries were semiautomatically measured in vivo, along the entire length exactly perpendicular to the lumen for the first time with the resolution that can be achieved using a modern CT scanner. The data can therefore be considered to be very exact. Based on these data, the originally required anatomical criteria for renal denervation can be thoroughly reviewed. They are fulfilled much less frequently than has been reported in literature up to now. However, this problem will probably be reduced or even eliminated in the future by more suitable devices that will make it possible to denervate renal arteries even with a diameter $<4 \mathrm{~mm}$, or a length $<20 \mathrm{~mm}$. Initial promising developments are already on the market ${ }^{40-42}$ or in the testing phase. ${ }^{43}$

In particular, due to the development of new devices for renal ablation, it can be assumed that the significance of anatomical variations as a complicating factor for renal denervation is already less than was anticipated based on the initial conditions, and will likely be reduced even more in the future. However, in order to discover what effect anatomical situations actually have on renal denervation, additional prospective observational studies will be necessary that take not only the number of renal arteries-as in the study by Verloop et $a l^{32}$-but also their origins, diameter, length and branching pattern into consideration. It may be assumed that the length of an artery is of less concern, and that ablation in the distal segment of a renal artery and the immediately following segments of the divisions of the renal arteries could be most effective because of the anatomical relationship of the nerves to the vessels $^{38}$-percutaneous approaches appear to be even more promising because the relation of the ablation area can be selected freely with respect to the position of the renal artery. An essential component of future studies must be the exact prior definition of the anatomical situation, which can be achieved only with high-quality, contrast-supported MRI-or better yet-CT angiographies, because the latter are less prone to artefacts.

There are also limitations to this study that should be mentioned. The small deviation of the frequency of multiple renal arteries $(35.7 \%)$ in comparison with the literature, can most likely be attributed to a bias due to the relatively small size of the sample. If we assume that average frequency of multiple renal arteries is $38.3 \%,{ }^{20}{ }^{21}$ the result is that even fewer than the $58.7 \%$ of patients reported here fail to fulfil the anatomical conditions. The percentage of patients in the group with arterial hypertension is unknown, and none of the patients included was actually denervated. However, there is nothing to suggest that the frequency of hypertension does not represent the incidence of the disease in the general population; on the other hand, no difference in the anatomical lumen sizes of arteries depending on blood pressure is known up to now, so data on blood pressure levels can be considered to be irrelevant. The risk factor, arterial hypertension, results in remodelling that reduces vascular lumen, ${ }^{44}$ so it can be assumed that arterial hypertension itself will be a factor that further limits the option of denervation.

In summary, this study shows that the renal arteries in humans have a wide funnel-shaped origin that is somewhat longer on the left side at up to $14 \mathrm{~mm}$ than on the right side. The main arteries are longer on the right side than on the left, have a somewhat smaller calibre on the right side, but are generally about $1 \mathrm{~mm}$ narrower than previously assumed. Most renal arteries have an ellipsoid cross-section. The implantation angles to the longitudinal axis of the aorta are somewhat more acute in caudal direction on the right than on the left. At $57.8 \%$, slightly more than half the patients did not fulfil the formal anatomical criteria for renal denervation.

\section{Author affiliations}

${ }^{1}$ Department of Radiology, Medical University of Innsbruck, Innsbruck, Tyrol, Austria

${ }^{2}$ University Clinic of Oral and Maxillofacial Surgery, Salzburg General Hospital, Salzburg, Salzburg, Austria

${ }^{3}$ Department of Neuroradiology, Medical University of Innsbruck, Innsbruck, Tyrol, Austria

${ }^{4}$ Department of Internal Medicine IV, Nephrology and Hypertensiology, Medical University of Innsbruck, Innsbruck, Tyrol, Austria

${ }^{5}$ Department of Urology, Medical University of Innsbruck, Innsbruck, Tyrol, Austria 
Contributors ES, RR, PN, JP and BG contributed to the conception and design of the work; the acquisition, analysis and interpretation of data for the work; in drafting the work and revising it critically for important intellectual content; and in giving final approval of the version to be published. ES and RR contributed equally to this work. AKL, AEG, JK and PR contributed to the acquisition of data for the work; in partially drafting the work and revising it critically for important intellectual content; and in giving final approval of the version to be published. All authors agreed to be accountable for all aspects of the work in ensuring that questions related to the accuracy or integrity of any part of the work are appropriately investigated and resolved.

Funding This research received no specific grant from any funding agency in the public, commercial or not-for-profit sectors.

Competing interests None declared.

Provenance and peer review Not commissioned; externally peer reviewed.

Data sharing statement The original data set is available by emailing the corresponding author, johannes.petersen@i-med.ac.at.

Open Access This is an Open Access article distributed in accordance with the Creative Commons Attribution Non Commercial (CC BY-NC 4.0) license, which permits others to distribute, remix, adapt, build upon this work noncommercially, and license their derivative works on different terms, provided the original work is properly cited and the use is non-commercial. See: http:// creativecommons.org/licenses/by-nc/4.0/

\section{REFERENCES}

1. [No authors listed]. Effects of treatment on morbidity in hypertension. Results in patients with diastolic blood pressures averaging 115 through 129 mm Hg. JAMA 1967;202:1028-34.

2. [No authors listed]. Effects of treatment on morbidity in hypertension. II. Results in patients with diastolic blood pressure averaging 90 through $114 \mathrm{~mm} \mathrm{Hg}$. JAMA 1970;213:1143-52.

3. Björk S, Sannerstedt R, Falkheden T, et al. The effect of active drug treatment in severe hypertensive disease: an analysis of survival rates in 381 cases on combined treatment with various hypotensive agents. Acta Med Scand 1961;169:673-89.

4. Sundstrom J, Arima H, Jackson R, et al. Effects of blood pressure reduction in mild hypertension: a systematic review and meta-analysis. Ann Intern Med 2015;162:184-91.

5. MacMahon S, Peto R, Cutler J, et al. Blood pressure, stroke, and coronary heart disease. Part 1, Prolonged differences in blood pressure: prospective observational studies corrected for the regression dilution bias. Lancet 1990;335:765-74.

6. Turnbull F, Blood Pressure Lowering Treatment Trialists Collaboration. Effects of different blood-pressure-lowering regimens on major cardiovascular events: results of prospectively-designed overviews of randomised trials. Lancet 2003;362:1527-35.

7. James PA, Oparil S, Carter BL, et al. 2014 Evidence-based guideline for the management of high blood pressure in adults: report from the panel members appointed to the eighth joint national committee (JNC 8). JAMA 2014;311:507-20.

8. Chobanian AV, Bakris GL, Black HR, Jr, et al. Seventh report of the Joint National Committee on Prevention, Detection, Evaluation, and Treatment of High Blood Pressure. Hypertension 2003;42: 1206-52.

9. Calhoun DA, Jones D, Textor S, et al. Resistant hypertension: diagnosis, evaluation, and treatment: a scientific statement from the American Heart Association Professional Education Committee of the Council for High Blood Pressure Research. Circulation 2008;117: e510-26.

10. Schlaich MP, Sobotka PA, Krum H, et al. Renal denervation as a therapeutic approach for hypertension: novel implications for an old concept. Hypertension 2009;54:1195-201.

11. Bravo EL, Rafey MA, Nally JV Jr. Renal denervation for resistant hypertension. Am J Kidney Dis 2009;54:795-7.

12. DiBona GF, Esler M. Translational medicine: the antihypertensive effect of renal denervation. Am J Physiol Regul Integr Comp Physiol 2010;298:R245-53.

13. Hendel MD, Collister JP. Renal denervation attenuates long-term hypertensive effects of angiotensin ii in the rat. Clin Exp Pharmacol Physiol 2006;33:1225-30.

14. Katholi RE, Winternitz SR, Oparil S. Decrease in peripheral sympathetic nervous system activity following renal denervation or unclipping in the one-kidney one-clip goldblatt hypertensive rat. J Clin Invest 1982;69:55-62.
15. Bakris GL, Townsend RR, Flack JM, et al. 12-Month blood pressure results of catheter-based renal artery denervation for resistant hypertension: the Symplicity HTN-3 trial. J Am Coll Cardiol 2015;65:1314-21.

16. Krum H, Schlaich $\mathrm{M}$, Whitbourn $\mathrm{R}$, et al. Catheter-based renal sympathetic denervation for resistant hypertension: a multicentre safety and proof-of-principle cohort study. Lancet 2009;373:1275-81.

17. Howard JP, Francis DP. Overcoming the three biases obscuring the science of renal denervation in humans: big-day bias, check-once-more bias and I-will-take-it-now bias. Trends Cardiovasc Med 2015;25:116-18.

18. Azizi M, Sapoval M, Gosse P, et al. Optimum and stepped care standardised antihypertensive treatment with or without renal denervation for resistant hypertension (DENERHTN): a multicentre, open-label, randomised controlled trial. Lancet 2015;385:1957-65.

19. Symplicity HTNI, Esler MD, Krum H, et al. Renal sympathetic denervation in patients with treatment-resistant hypertension (the Symplicity HTN-2 trial): a randomised controlled trial. Lancet 2010;376:1903-9.

20. Glodny B, Rapf K, Unterholzner V, et al. Accessory or additional renal arteries show no relevant effects on the width of the upper urinary tract: a 64-slice multidetector CT study in 1072 patients with 2132 kidneys. Br J Radiol 2011;84:145-52.

21. Glodny B, Nasseri P, Plaikner M, et al. Prediction of the presence of renal artery stenosis by calcium scoring of the abdominal aorta. Eur $J$ Radiol 2012;81:1393-9.

22. Glodny B, Cromme S, Reimer $\mathrm{P}$, et al. Hypertension associated with multiple renal arteries may be renin-dependent. $J$ Hypertens 2000;18:1437-44

23. Talenfeld AD, Schwope RB, Alper HJ, et al. MDCT angiography of the renal arteries in patients with atherosclerotic renal artery stenosis: implications for renal artery stenting with distal protection. AJR Am J Roentgenol 2007;188:1652-8.

24. Palmieri BJ, Petroianu A, Silva LC, et al. Study of arterial pattern of 200 renal pedicle through angiotomography. Rev Col Bras Cir 2011;38:116-21.

25. Ramadan SU, Yigit H, Gokharman D, et al. Can renal dimensions and the main renal artery diameter indicate the presence of an accessory renal artery? A 64-slice CT study. Diagn Interv Radiol 2011;17:266-71.

26. Conway BD, Greenberg RK, Mastracci TM, et al. Renal artery implantation angles in thoracoabdominal aneurysms and their implications in the era of branched endografts. J Endovasc Ther 2010;17:380-7.

27. Friesinger GC, Page EE, Ross RS. Prognostic significance of coronary arteriography. Trans Assoc Am Physicians 1970;83: 78-92.

28. Sakakura K, Ladich E, Cheng Q, et al. Anatomic assessment of sympathetic peri-arterial renal nerves in man. $J$ Am Coll Cardiol 2014;64:635-43.

29. Persu $A$, Jin $Y$, Baelen $M$, et al. Eligibility for renal denervation: experience at 11 European expert centers. Hypertension 2014;63:1319-25

30. Zhang HL, Sos TA, Winchester PA, et al. Renal artery stenosis: imaging options, pitfalls, and concerns. Prog Cardiovasc Dis 2009;52:209-19.

31. Vasbinder GB, Nelemans PJ, Kessels AG, et al. Diagnostic tests for renal artery stenosis in patients suspected of having renovascular hypertension: a meta-analysis. Ann Intern Med 2001; 135:401-11.

32. Verloop WL, Vink EE, Spiering W, et al. Renal denervation in multiple renal arteries. Eur J Clin Invest 2014:44:728-35.

33. Atherton DS, Deep NL, Mendelsohn FO. Micro-anatomy of the renal sympathetic nervous system: a human postmortem histologic study. Clin Anat 2012;25:628-33.

34. Kuo DC, Nadelhaft I, Hisamitsu T, et al. Segmental distribution and central projections of renal afferent fibers in the cat studied by transganglionic transport of horseradish peroxidase. J Comp Neurol 1983;216:162-74.

35. Ammons WS. Bowditch lecture. Renal afferent inputs to ascending spinal pathways. Am J Physiol 1992;262(2 Pt 2):R165-76.

36. Barajas L, Liu L, Powers K. Anatomy of the renal innervation: intrarenal aspects and ganglia of origin. Can J Physiol Pharmacol 1992;70:735-49.

37. Glodny B, Petersen J, Hofmann KJ, et al. Kidney fusion anomalies revisited: clinical and radiological analysis of 209 cases of crossed fused ectopia and horseshoe kidney. BJU Int 2009;103:224-35.

38. Esler M. Illusions of truths in the Symplicity HTN-3 trial: generic design strengths but neuroscience failings. J Am Soc Hypertens 2014;8:593-8. 
39. Bhatt DL, Kandzari DE, O'Neill WW, et al. A controlled trial of renal denervation for resistant hypertension. N Engl J Med 2014;370:1393-401.

40. Verheye S, Ormiston J, Bergmann MW, et al. Twelve-month results of the rapid renal sympathetic denervation for resistant hypertension using the OneShotTM ablation system (RAPID) study. Eurolntervention 2015;10:1221-9.

41. Sievert H, Schofer J, Ormiston J, et al. Renal denervation with a percutaneous bipolar radiofrequency balloon catheter in patients with resistant hypertension: 6-month results from the reduce-HTN clinical study. Eurolntervention 2015;10:1213-20.
42. Papademetriou V, Tsioufis CP, Sinhal A, et al. Catheter-based renal denervation for resistant hypertension: 12-month results of the EnligHTN I first-in-human study using a multielectrode ablation system. Hypertension 2014;64: 565-72.

43. Prochnau D, Lucas N, Kuehnert $\mathrm{H}$, et al. Catheter-based renal denervation for drug-resistant hypertension by using a standard electrophysiology catheter. Eurolntervention 2012;7:1077-80.

44. Gibbons GH, Dzau VJ. The emerging concept of vascular remodeling. N Engl J Med 1994;330:1431-8. 